\title{
Theoretical study on the atmospheric degradation mechanism and subsequent products of E,E-2,4-hexadienal with hydroxyl radical
}

\author{
Yanan Sun ${ }^{1}$, Junfang Yao ${ }^{1}$, Yizhen Tang ${ }^{1}$, yunju zhang ${ }^{2}$, Wenzhong $\mathrm{Wu}^{1}$, and Jingyu Sun $^{1}$ \\ ${ }^{1}$ Hubei Normal University \\ ${ }^{2}$ Mianyang Normal University
}

September 21, 2020

\begin{abstract}
E,E-2,4-hexadienal is probably a precursor of secondary organic aerosol (SOA) and plays an important role in the atmospheric chemistry. Its main degradation routs are the reactions with $\mathrm{OH}, \mathrm{Cl}, \mathrm{NO} 3$ as well as photolysis. Atmospheric hydroxyl radical, as the most important oxidant, generally controls the removal of volatile organic compounds (VOCs) in the atmosphere. Thus, the quantum chemical calculations are used to investigate the reaction mechanism of E,E-2,4-hexadienal with hydroxyl radical, which would give better understanding for the main degradation products. The reaction paths of E,E-2,4-hexadienal with OH radical have been calculated accurately at the BMC-CCSD//M06-2X/6-311G (d, p) level at atmospheric pressure and room temperature. There are six hydrogen abstraction and four carbon addition paths at the first stages of this reaction. Due to the low energy barrier and reaction exotherm, the ten paths would contribute to the total reaction. Furthermore, the peroxy (RO2) and alkoxy (RO) radicals from the most important adduct IM1 $(\mathrm{CH} 3 \mathrm{CHOHCHCH}=\mathrm{CHCHO}$ ) would be formed in the atmospheric environment. The reaction mechanism of the peroxy radical $(\mathrm{CH} 3 \mathrm{CHOHCHO} 2 \mathrm{CH}=\mathrm{CHCHO})$ with $\mathrm{NO}$, $\mathrm{NO} 2$, $\mathrm{HO} 2$, and self-reaction have been studied by using the same quantum chemical methods. And the reaction paths of alkoxy radical $(\mathrm{CH} 3 \mathrm{CHOHCHOCH}=\mathrm{CHCHO})$ have been also originally studied. The subsequent reactions play a key role in the cycling of atmospheric radicals, production of ozone, and SOA formation. What's more, the reaction mechanism of this study accords with the reported experimental observations.
\end{abstract}

\section{Hosted file}

manuscript.pdf available at https://authorea.com/users/360798/articles/482336-theoreticalstudy-on-the-atmospheric-degradation-mechanism-and-subsequent-products-of-e-e-2-4hexadienal-with-hydroxyl-radical 